\title{
The Importance of Apoptosis in Cancer Development and Treatment
}

\author{
(D) İrem Nur GÖKBAYRAK ATAY, ${ }^{1}$ (1) Ayhan Hilal GEZER, ${ }^{2}$ (1) Elmas KASAP ${ }^{3}$ \\ 'Department of Neuroscience, Dokuz Eylül University Faculty of Health Sciences Institute, Izmir-Turkey \\ ${ }^{2}$ Department of Medical Biology, Celal Bayar University Faculty of Medicine, Manisa-Turkey \\ ${ }^{3}$ Department of Internal Medicine and Gastroenterology, Celal Bayar University Faculty of Medicine, Manisa-Turkey
}

\begin{abstract}
SUMMARY
Cancer is one of the most important causes of death in our era. Multifactorial causes are involved in the formation of cancer. The reduction of apoptosis is one of these reasons. Failure to activate apoptosis pathways can lead to resistance to the current treatment approaches of cancers. A better understanding of the molecular events that regulate apoptosis in cancers and cancer therapy form the basis of a more rational approach to the development of molecular targeted therapies in the fight against cancer.
\end{abstract}

Keywords: Apoptosis; apoptosis pathways; cancer; cancer development; cancer treatment.

Copyright $\odot$ 2021, Turkish Society for Radiation Oncology

\section{Introduction}

Apoptosis is the programmed death of the cells, which are not needed and whose functions are impaired without harming the environment, as a requirement of intercellular relations in developed organisms. Starting from the embryo period, there is apoptotic mechanism and programmed cell death throughout life. Some cells live for years, while some live only a few hours. Continuity in many tissues such as skin, gastrointestinal system, and immune system is dependent on apoptosis and cell renewal.[1]

Apoptosis is one of the most acceptable mechanisms for anticancer activity in cancer cells. The regulatory mechanisms of apoptosis are very complex. Reactive oxygen species, caspase activation, tumor necrosing factor (TNF), protein kinase, and mitochondrial pathway form the basis of apoptosis. [2]

\section{What Is Cancer?}

Cancer has been a common problem in humans and animals throughout the known history. The earliest

Received: December 29, 2020

Accepted: January 10, 2021

Online: June 16, 2021

Accessible online at:

www.onkder.org

OPEN ACCESS This work is licensed under a Creative Commons

Attribution-NonCommercial 4.0 International License. known records about cancer date back to 3000 BC. The word cancer is derived from the words "canker" or "carcinos," which means crab in Latin. The term tumor was first used by Hippocrates in the $3^{\text {rd }}$ century BC because it compared the swollen veins around the tumor to the legs of a crab, and the term "oncos," which means swelling, was used.[3]

Cancer is a complex disease caused by uncontrolled division and proliferation of cells and under the influence of genetic and environmental conditions. Cancer is also a personal disease, although there are more than 100 known types of cancer and standard approaches have been developed for certain types of cancers. Cancer is the uncontrolled division, proliferation, and accumulation of cells in an organism. It can affect a single organ as well as spread to distant organs and show its effect.[3] Cancer is a disease associated with a decrease in apoptosis.[4]

\section{What Is Apoptosis?}

Apoptosis is a word formed by the combination of ancient Greek apo (separate) and ptosis (fall) and used by

MSc. Ayhan Hilal GEZER

Celal Bayar Üniversitesi Tıp Fakültesi,

Tıbbi Biyoloji Anabilim Dalı,

Manisa-Turkey

E-mail: hilalgezer@hotmail.com 
Homeres to describe leaf fall in autumn. For this reason, it is the type of cell death that occurs when some cells dry up like autumn leaves and leave the body and make room for the cells coming from behind. It was named "apoptosis" with the suggestion of the classical Greek historian James Cormack.[5]

Apoptosis; it is programmed cell death, which is an important cell growth control component that ensures the elimination of cells that are not needed, whose functions are impaired, that have completed their biological task or are damaged after exposure to a certain stimulus.[6]

There are two pathways in apoptosis: Extrinsic pathway and intrinsic pathway. $[7,8]$

\section{Extrinsic Pathway (Receptor Pathway)}

This pathway is stimulated by the tumor necrosis factor-alpha (TNF-alpha) family, which binds to the CD95 ligand (Fas ligand=CD95L) by extracellular signals. This binding causes the formation of deathinducing signal complex (DISC) by causing conformational changes independent of ATP at the receptor. With the CD95 adapter molecule Fas receptor-associated measurement unit (FADD), FADD also combines with procaspase- 8 and procaspase- 10 to form the DISC complex. Separation of small and large subunits is not required for activation. The next step is activation of procaspase-8, causing proteolysis from caspase- 3 to separate from the small subunit, thereby activating the enzyme. This pathway combines with the mitochondrial pathway through the caspase- 3 activation, thereby strengthening the apoptosis signal. Cellular FLICE-inhibiting proteins (cFLIP, cFLIPL, cFLIPs) can combine with DISC to inhibit the activation of caspase- 8 and 10 , preventing apoptosis.[7,9]

\section{Instrinsic Pathway (Mitochondrial Pathway)}

Unlike this pathway death receptor pathway, it can be induced by both extracellular signals (growth factor or hormone deficiency, ultraviolet beam, and various cytokines) and intracellular signals that cause DNA damage. While the intracellular signal stimulates the proapoptotic members of the $\mathrm{Bcl}-2$ family, it migrates to the mitochondria, while the proapoptotic members settle on the outer mitochondrial membrane and form pores (mitochondrial passages) here. These pores allow cytochrome-c separation from mitochondria. Cytochrome c; Combining with apaf-1, ATP, dATP, and procaspase-9, the apoptosome activates caspase-3. Although their beginnings are different, they both result in caspase- 3 activation in both pathways. Furthermore, apoptosis-inducing factor (AIF) from mitochondria is released in molecules such as G, Smac/DIABLO, and $\mathrm{Omi} / \mathrm{HtrA}$. Endonuclease $\mathrm{G}$ and AIF, while inducing DNA fragmentation, Smac/DIABLO, and Omi/HtrA2 neutralize apoptosis-inhibiting protein (nnhibitor of apoptosis proteins [IAPs]). Molecules such as Smac/ DIABLO and Omi/HtrA2 are located in the intermembrane region of the mitochondria, such as cytochrome c. Smac/DIABLO and Omi/HtrA2 have many similar aspects. However, while Smac/DIABLO is not found in the heart and detected in the brain, on the other hand, there is a widespread distribution of Omi/HtrA2.[7,9]

\section{Apoptosis and Cancer Relationship}

In cancer, an important disease associated with apoptosis, the balance between cell proliferation and cell death is disrupted, and cells are unable to receive death signals to cause apoptosis. This can cause problems at any step of the apoptotic pathways. Better understanding of the molecular events regulating apoptosis mechanisms enables the creation or development of new treatment options for the activation or inhibition of the target molecules in these pathways.[10]

The irregularity of apoptotic pathways not only promotes tumor formation but can also make the cancer cell resistant to treatment. Therefore, irregularity of apoptosis is an important cancer symptom.[11]

As with B cell lymphoma, decreased apoptosis in some tumors can cause tumor development. In general, an increase in apoptosis is observed due to the increase in proliferation in tumor tissue.[12]

Disorders in programmed cell death (apoptosis) mechanisms play important roles in tumor pathogenesis. Apoptosis allows neoplastic cells to survive over their intended lifespan, reduces the need for exogenous survival factors, and provides protection from oxidative stress and hypoxia as the tumor mass expands. [13] It has been found that anti-apoptotic Bcl-2 subgroup is induced in many types of cancer. And it has been determined that the levels of inhibitors are induced in tumor cell lines. Tumor by inducing the molecule level can cause deproliferation or apoptosis. For example, IL-3 induces the Bcl-xL level to improve survival of the myeloid sequence and interleukin IL-5 and IL-15 protect eosinophils and mast cells from apoptosis by inducing the Bcl-xL level.[14] 
In chronic lymphocytic leukemia, IL-4 levels increase, excessive production of $\mathrm{Bcl}-2$ occurs, and the life span of malignant B cells is prolonged. Two antiapoptotic cytokines IL- 4 and IL-10 are released in thyroid carcinoma cells and contribute to cancer development.[15] There are kinds of molecular mechanisms that tumor cells use to suppress apoptosis. Tumor cells can become resistant to apoptosis by the expression of antiapoptotic proteins such as Bcl-2 or by down-regulation or mutation of proapoptotic proteins such as BAX.[16] Some forms of human B cell lymphoma have $\mathrm{Bcl}-2$ overexpression. This example represents the first and strongest evidence that the absence of apoptosis contributes to cancer.[17]

\section{p53 and Cancer}

The first gene therapy product used in cancer treatment is Gendicine, which is specifically designed to express p53 (rAd-p53). In a study conducted on patients with oral cancer, it has been shown that administration of rAd-p53 infusion together with chemotherapy significantly increases the survival rate in patients. Apart from that, it has been stated that it is used effectively in hepatocellular carcinoma, tongue cancer, and some other types of cancer.[18-20]

Regulation of apoptosis in humans is a process that starts with p53 and continues up to caspases. Cell life is prolonged when $\mathrm{p} 53$, which works as a tumor suppressor gene, is mutated or absent. Cell damage caused by genotoxic events activates a transcription regulator gene, $\mathrm{p} 53$. After the $\mathrm{p} 53$ protein product binds directly to DNA and recognizes the damage, it either induces cell cycle arrest in G1, gaining time for repair, or directs apoptosis if the damage is greater. In addition, p53 is thought to regulate the ratios of $\mathrm{Bax} / \mathrm{Bax}, \mathrm{Bax} / \mathrm{Bcl}-2$, and $\mathrm{Bcl}-2 / \mathrm{Bcl}-2$ groups.[21]

\section{Caspases and Cancer}

Although the mechanism of apoptosis is not fully explained, the most important event associated with apoptosis is the activation of caspases. [1,22]

Initiator caspases transmit death signals initiated by apoptotic stimulation to effector caspases. Effector caspases, on the other hand, break down related proteins and cause the formation of apoptotic cell morphology. Defects in the caspase can contribute to autoimmune diseases, cancer, and the formation of some neurological disorders. $[23,24]$

\section{IAPs and Cancer}

IAP (inhibitors of apoptosis), a family of caspase inhibitors, selectively inhibit caspases. Thus, they stop the apoptotic mechanism. These inhibitors are expressed by many malignant cells. IAPs can also stop apoptosis by affecting the cell cycle.[23]

IAPs are a group of structurally and functionally similar proteins that regulate apoptosis, cytokinesis, and signal transduction. They are characterized by the presence of a baculovirus IAP repeat (BIR) protein domain.[25]

Irregular IAP expression has been reported in many cancers. For example, Lopes et al.,[26] it showed that the abnormal expression of the IAP family in pancreatic cancer cells and this abnormal expression is also responsible for resistance to chemotherapy. Among the IAPs tested, the study concluded that drug resistance was the most significant correlation with cIAP-2 expression in pancreatic cells.

Survivin, another IAP, has been reported to be overexpressed in various cancers. Small et al.,[27] transgenic mice overexpressing Survivin in hematopoietic cells are high in terms of hematological malignancy risk and observed that hematopoietic cells designed to overexpress Survivin are less susceptible to apoptosis.

Survivin has been found to be overexpressed in non-small cell lung carcinomas (NSCLC) in conjunction with XIAP. It has been concluded that Survivin overexpression in most NSCLCs is accompanied by excess or upregulated expression of XIAP.[28]

\section{Carcinogenesis by Intrinsic Apoptosis Pathway Mutations}

The intrinsic apoptosis pathway is one of the most important pathways for apoptosis induction. Therefore, disrupting this pathway is an effective way of preventing apoptosis. $\mathrm{Bcl}-2$ family proteins ( $\mathrm{c}=24$ in humans) are central regulators of the intrinsic pathway, either suppressing or promoting changes in mitochondrial membrane permeability required for the release of cyt-c and other apoptogenic proteins. [29,30]

Antiapoptotic proteins block the death signal by partially antagonizing the effects of Bax/Bak through known mechanisms. Furthermore, antiapoptotic proteins prevent Bax/Bak activation by sequestrating/inhibiting BH3-only proteins "activator" and/or directly inhibiting Bax/Bak activation. [29] 
Antiapoptotic proteins (e.g., Bcl-2, Bcl-xL, Bcl-W, Mcl-1, and Bfl-1/A1, which exhibit sequence homology in all BH1-BH4 domains) increase cell survival, while proapoptotic proteins are receptor, endoplasmic reticulum (ER), or mitochondria. ER mediates stressinduced apoptosis. The next group contains proteins that contain the multi-domain or BH3- only. The first consists of Bax and Bak, which are necessary for apoptosis.[31]

The central role played by Bax/Bak in apoptosis is supported by studies that $\mathrm{BH} 3$-only proteins do not induce apoptosis in cells with Bax/Bak deficiency.[32,33]

\section{Carcinogenesis by Extrinsic Apoptosis Pathway Mutations}

It is activated in vivo by TNF family ligands that bind DD-containing receptors, which means that DED-containing caspases lead to its activation. "Death ligands" are expressed on CTLs, NK cells, and other immunerelated cells (activated monocytes/macrophages and nitrite cells) and are used as weapons for destroying transformed cells.[34]

Another molecule, c-FLIP, which regulates caspase- 8 activation, is c-FLIP $(\mathrm{L})$, which are long IL- $1 \beta$ converting enzyme inhibitor proteins similar to cellular FADD. Another molecule, c-FLIP, which regulates caspase- 8 activation, is c-FLIP (L), which are long interleukin-1 beta converting enzyme inhibitor proteins similar to cellular FADD. [35,36]

Melanoma, hepatocellular carcinoma, non-small cell lung carcinoma[37] and endometrial,[38] colon, [39] and prostate cancer,[40] including increased expression of c-FLIP has been detected in many human malignancies. Its overexpression is associated with cancer progression and/or poor prognosis in $\mathrm{BL}$, HCC, and ovarian, endometrial, colon, and prostate cancer. [35,36,39]

The high expression of C-FLIP blocks caspase-8 and makes cells resistant to cell receptor-mediated apoptosis.[35] Overexpression of C-FLIP has been reported to bind proteins involved in these signaling pathways, including TRAF1, TRAF2, RIP, and RAF1, thereby promoting the activation of NF-kB and ERK as downstream molecules. [36]

Mice-based studies on the use of neutralizing antibodies and Fc-fusion proteins as well as genetic changes in genes encoding death ligands or their receptors, found that death ligands and the genes encoding them play important roles in tumor sup- pression by cellular immune mechanisms. aFas ligand (FasL) is important for CTL-mediated killing of some tumor targets, and TRAIL (Apo2 ligand) is critical for NK-mediated tumor suppression. Some tumor cells resist the death receptor pathway's response to FasL produced by $\mathrm{T}$ cells to avoid immune damage. Many tumor cells show intrinsic resistance to TRAIL. This directly sequesters Fas of ligand or expression Fas ligand on the surface of tumor cells. This is downregulation of the Fas receptor, a dysfunctional Fas receptor, and it creates the secretion of high levels of Fas receptor.[41] Some tumor cells may undertake a Fas ligand-mediated "counterattack" causing apoptotic depletion of active tumor-infiltrating lymphocytes.[42]

\section{Apoptosis and Cancer Treatment}

Cancer-related defects in apoptosis play a role in resistance to treatment with traditional treatments such as chemotherapy and radiotherapy, increasing the cell death threshold, thus requiring higher doses of tumoricidal agents.[43]

Apoptosis and Cancer Theratment targets apoptosis via receptor-chondrial-mediated. Many drugs are used in cancer treatment today to kill cells. Disruption of mitochondrial membrane potential, cytochrome c release, and activation of different caspases have been identified following treatment of cells with different chemotherapeutic agents (Table 1).[44,45]

Tumor selective expression of proapoptotic Bax by adenoviral gene transfer leads to selective toxicity in tumor cells.[46]

Bortezomib has a sensitive effect on apoptosis induced by NF- $\kappa \mathrm{B}$ suppression by downregulated Bcl-2. [47] On the other hand, it has been reported that $\mathrm{BH} 3$ proteins Bik and Bim levels, which are an important mediator of antitumor activity, increase in various cell lines through bortezomib.[48] Heat shock proteins are also pharmacological targets. Geldanamycin, an Hsp 90 inhibitor, shows a clear antitumor effect.[49] The drug known as eurycoma has proven excellent antiproliferative and anticancer effectiveness against a variety of human cancers in most in vitro and in vivo studies. Eurycoma mechanism of action; it is the induction of apoptosis and down-regulation of expression by up-regulation of p53 (tumor suppressor protein) and proapoptotic protein (Bax) expression and down-regulation of expression.[50] 


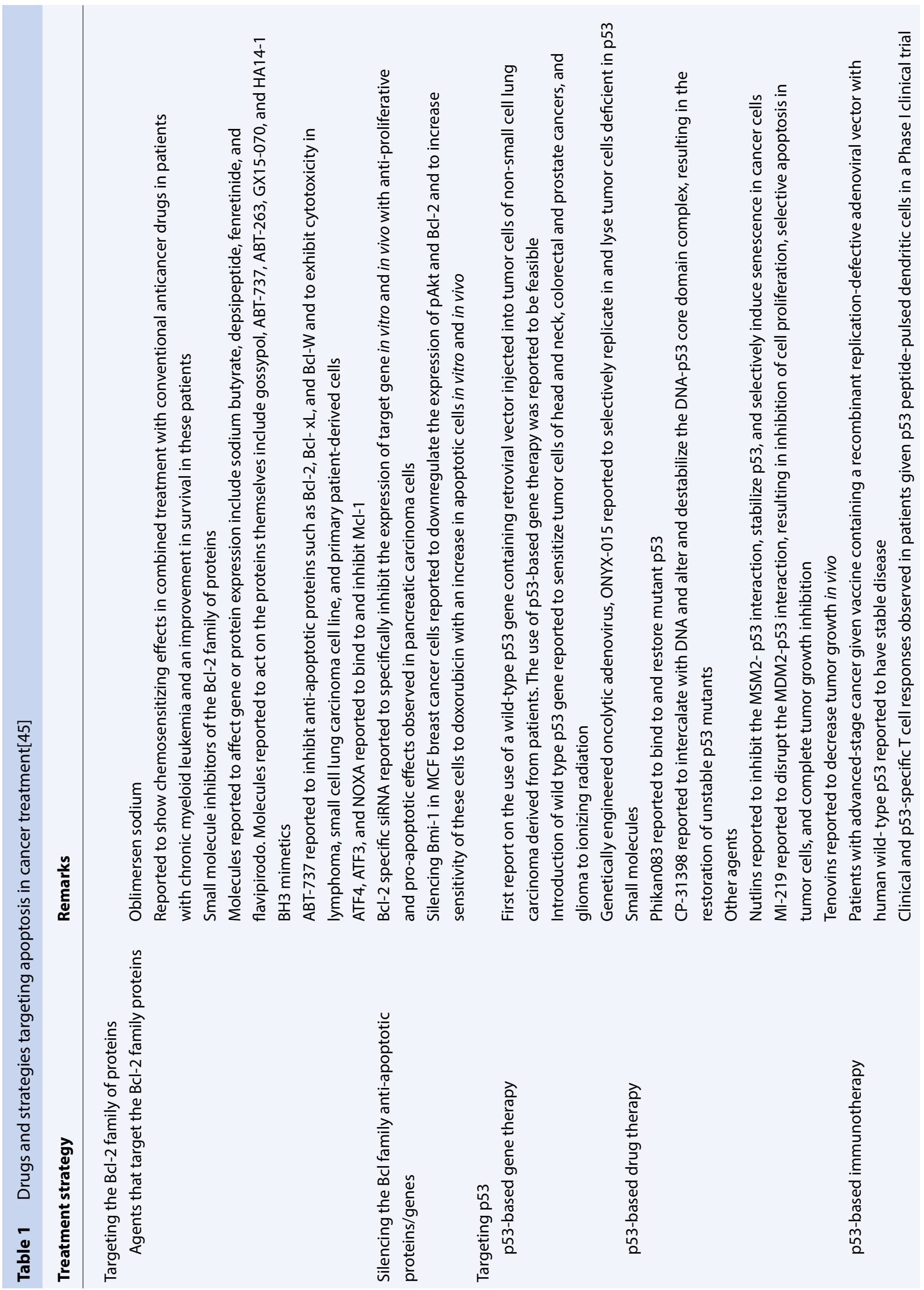




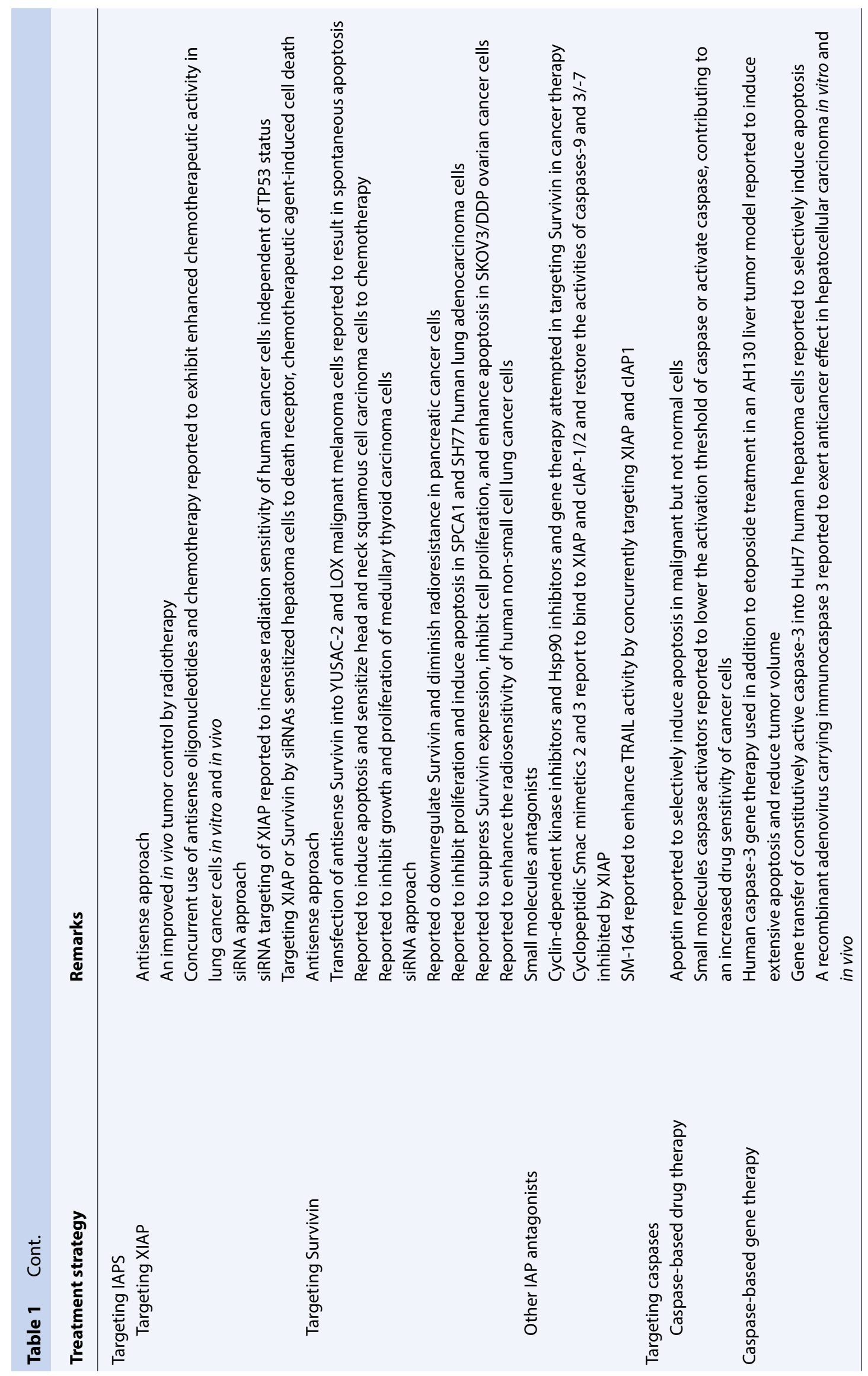




\section{Conclusion}

Demonstrating the relationship between the cell apoptosis system and its elements with cancer may allow the causes of cancer to be determined and resolved in a case and effect relationship. In addition, it may open new horizons in cancer treatment using agents associated with the apoptotic system against cancer. Thus, effective cancer treatment can be demonstrated.

Peer-review: Externally peer-reviewed.

Conflict of Interest: Authors declare no conflict of interest.

Financial Support: No financial support has been used for this study.

\section{References}

1. Cohen JJ. Apoptosis to be or not to be. Vol. 1. Postgraduate Syllabus (AA-AA-I); 1998. p. 1-19.

2. Sanmartín C, Plano D, Palop JA. Selenium compounds and apoptotic modulation: A new perspective in cancer therapy. Mini Rev Med Chem 2008;8(10):1020-31.

3. Baykara O. Current Modalities in Treatment of Cancer. Balikesir Saglik Bil Derg Cilt: 5 Sayı: 3; 2016.

4. Fadeel B, Orrenius S, Zhivotovsky B. Apoptosis in human disease: A new skin for the old ceremony? Biochem Biophys Res Commun 1999;266(3):699-717.

5. Cummings MC, Winterfold CM, Walker NI. Apoptosis. Am J Surg Pathal 1997;21(1):88-101.

6. Koff JL, Ramachandiran S, Bernal-Mizachi L. A time to kill: Targeting apoptosis in cancer. Int J Mol Sci 2015;16(2):2942-55.

7. Sprick MR, Walczak $H$. The interplay between the Bcl-2 family and death receptor-mediated apoptosis. Biochim Biophys Acta 2004;1644(2-3):125-32.

8. Falschlehner C, Emmerich CH, Gerlach B, Walczak H. TRAIL signalling: Decisions between life and death. Int J Biochem Cell Biol 2007;39(7-8):1462-75.

9. Barnhart BC, Alappat EC, Peter ME. The CD95 Type I/Type II model. Semin Immunol 2003;15(3):185-93.

10. Nitulescu GM, Draghici C, Olaru OT, Matei L, Loana A, Dragu LD, et al. Synthesis and apoptotic activity of new pyrazole derivatives in cancer cell lines. Bioorg Med Chem 2015;23(17):5799-808.

11. Hanahan D, Weinberg RA. The hallmarks of cancer. Cell 2000;100(1):57-70.

12. Soini Y, Paakkö P, Lehto VP. Histopathological evaluation of apoptosis in cancer. Am J Pathol 1998;153(4):1043-9.

13. BenJilani KE, Gaillard JP, Petit F, Arnoult D, Roumier AS, Labalette M, et al. A suppressive effect of the ade- novirus 5 protein E1B $55 \mathrm{~K}$ on apoptosis induced by IL-3 deprivation and gamma-irradiation. Biol Cell 2002;94(2):77-89.

14. Mehmet H, Laurenzi VD, Stassi G, Walczak H. Programmed cell death in disease. In: Teaching Workshop on Apoptosis. $1^{\text {st }}$ ed. İzmir: Dokuz Eylül University Institute of Health Sciences; 2006. p. 12-7.

15. Miyashita T, Krajewski S, Krajewska M, Wang HG, Lin HK, Liebermann DA, et al. Tumor suppressor p53 is a regulator of bcl-2 and baxgene expression in vitro and in vivo. Oncogene 1994;9(6):1799-805.

16. Vaux DL. Immunopathology of apoptosis introduction and overview. Springer Semin Immunopathol 1998;19(3):271-8.

17. Call JA, Eckhardt SG, Camidge DR. Targeted manipulation of apoptosis in cancer treatment. Lancet Oncol 2008;9(10):1002-11.

18. Sheng S, Zheng J, Cui S, Cui X, Qian Z. Complete remission of multiple lung metastases after ablation of hepatocellular carcinoma by transarterial infusion with the p53 gene. Anticancer Drugs 2015;26(2):22731.

19. Shen A, Liu S, Yu W, Deng H, Li Q. p53 gene therapy-based transarterial chemoembolization for unresectable hepatocellular carcinoma: A prospective cohort study. J Gastroenterol Hepatol 2015;30(11): 1651-6.

20. Israels LG, Israels ED. Apoptosis. Oncologist 1999;4(4):332-9.

21. Choen GM. Caspases: The executioners of apoptosis. Biochem J 1997;326(1):1-16.

22. Lee D, Scott AL, Jerry AL. Potent and selective nonpeptide inhibitors of caspases 3 and 7 inhibit apoptosis and maintain cell functionality. J Biol Chem 2000;275(21):16007-14.

23. Kidd VJ, Lahti JM, Teitz T. Proteolytic regulation of apoptosis. Semin Cell Dev Biol 2000;11(3):191-201.

24. Norberg E, Orrenius S, Zhivotovsky B. Mitochondrial regulation of cell death: Processing of apoptosis-inducing factor (AIF). Biochem Biophys Res Commun 2010;396(1):95-100.

25. LaCasse EC, Mahoney DJ, Cheung HH, Plenchette S, Baird S, Korneluk RG. IAP-targeted therapies for cancer. Oncogene 2008;27(48):6252-75.

26. Lopes RB, Gangeswaran R, McNeish IA, Wang Y, Lemoine NR. Expression of the IAP protein family is dysregulated in pancreatic cancer cells and is important for resistance to chemotherapy. Int J Cancer 2007;120(11):2344-52.

27. Small S, Keerthivasan G, Huang Z, Gurbuxani $\mathrm{S}$, Crispino JD. Overexpression of survivin initiates haematologic malignancies in vivo. Leukaemia 
2010;24(11):1920-6.

28. Krepela E, Dankova P, Moravcikova E, Krepelova A, Prochazka J, Cermak J, et al. Increased expression of inhibitor of apoptosis proteins, Survivin and XIAP, in non-small cell lung carcinoma. Int J Oncol 2009;35(6):1449-62.

29. Green DR, Kroemer G. The pathophysiology of mitochondrial cell death. Science 2004;305(5684):626-9.

30. Motyka B, Korbutt G, Pinkoski MJ, Heibein JA, Caputo A, Hobman M, et al. Mannose 6-phosphate/insulin-like growth factor II receptor is a death receptor for granzyme B during cytotoxic T cell-induced apoptosis. Cell 2000;103(3):491-500.

31. Reed JC. Proapoptotic multidomain Bcl-2/Baxfamily proteins: Mechanisms, physiological roles, and therapeutic opportunities. Cell Death Differ 2006;13(8):1378-86.

32. Wei MC, Zong WX, Cheng EH, Lindsten T, Panoutsakopoulou V, Ross AJ, et al. Proapoptotic BAX and BAK: A requisite gateway to mitochondrial dysfunction and death. Science 2001;292(5517):727-30.

33.Zong WX, Lindsten T, Ross AJ, MacGregor GR, Thompson CB. BH3-only proteins that bind prosurvival Bcl-2 family members fail to induce apoptosis in the absence of Bax and Bak. Genes Dev 2001;15(12):1481-6.

34. Locksley RM, Killeen N, Lenardo MJ. The TNF and TNF receptor superfamilies: Integrating mammalian biology. Cell 2001;104(4):487-501.

35. Bagnoli M, Canevari S, Mezzanzanica D. Cellular FLICE-inhibitory protein (c-FLIP) signalling: A key regulator of receptor-mediated apoptosis in physiologic context and in cancer. Int J Biochem Cell Biol 2010;42(2):210-3.

36. Safa AR, Day TW, Wu CH. Cellular FLICE-like inhibitory protein (C-FLIP): A novel target for cancer therapy. Curr Cancer Drug Targets 2008;8(1):37-46.

37. Wilson TR, Redmond KM, McLaughlin KM, Crawford N, Gately K, O'Byrne K, et al. Procaspase 8 overexpression in non-small-cell lung cancer promotes apoptosis induced by FLIP silencing. Cell Death Differ 2009;16(10):1352-61.

38. Chen LY, Chen TH, Wen PY, Chou CH, Ying TH, Chang SP, et al. Differential expression of NUDT9 at different phases of the menstrual cycle and in different components of normal and neoplastic human en- dometrium. Taiwan J Obstet Gynecol 2009;48(2):96107.

39. Korkolopoulou P, Saetta AA, Levidou G, Gigelou F, Lazaris A, Thymara I, et al. c-FLIP expression in colorectal carcinomas: Association with Fas/FasL expression and prognostic implications. Histopathology 2007;51(2):150-6.

40. Gao S, Wang H, Lee P, Melamed J, Li CX, Zhang F, et al. Androgen receptor and prostate apoptosis response factor- 4 target the c-FLIP gene to determine survival and apoptosis in the prostate gland. J Mol Endocrinol 2006;36(3):463-83.

41. Elmore S. Apoptosis: A review of programmed cell death. Toxicol Pathol 2007;35(4):495-516.

42. Koyama S, Koike N, Adachi S. Fas receptor counterattack against tumor-infiltrating lymphocytes in vivo as a mechanism of immune escape in gastric carcinoma. J Cancer Res Clin Oncol 2001;127(1):20-6.

43. Makinand G, Hickman JA. Apoptosis and cancer chemotherapy. Cell Tissue Res 2000;301(1):143-52.

44. Kroemer G, Reed JC. Mitochondrial control of cell death. Nat Med 2000;6(5):513-9.

45. Wong RS. Apoptosis in cancer: From pathogenesis to treatment. J Exp Clin Cancer Res 2011;30(1):87.

46. Tai YT, Strobel T, Kufe D, Cannistra SA. In vivo cytotoxicity of ovarian cancer cells through tumor-selective expression of the Bax gene. Cancer Res 1999;59:2121-6.

47. Fahy BN, Schlieman MG, Mortenson MM, Virudachalam S, Bold RJ. Targeting BCL-2 overexpression in various human malignancies through NF-kappaB inhibition by the proteasome inhibitor bortezomib. Cancer Chemother Pharmacol 2005;56:46-54.

48. Nikrad M, Johnson T, Puthalalath H, Coultas L, Adams J, Kraft AS. The proteasome inhibitor bortezomib sensitizes cells to killing by death receptor ligand TRAIL via $\mathrm{BH} 3$-only proteins Bik and Bim. Mol Cancer Ther 2005;4(3):443-9.

49. Blagosklonny MV.Hsp-90-associated oncoproteins: Multiple targets of geldanamycin and its analogs. Leukemia 2002;16(4):455-62.

50. Thu HE, Hussain Z, Mohamed IN, Shuid AN. Eurycoma longifolia, A potential phytomedicine for the treatment of cancer: Evidence of p53-mediated apoptosis in cancerous cells. Curr Drug Targets 2018;19(10):1109-26. 